\title{
BACKSCATTER ANALYSIS USING MULTI-TEMPORAL SENTINEL-1 SAR DATA FOR CROP GROWTH OF MAIZE IN KONYA BASIN, TURKEY
}

\author{
S. Abdikan ${ }^{1 *}$, A. Sekertekin ${ }^{2}$, M. Ustunern ${ }^{3}$, F. Balik Sanli ${ }^{3}$, R. Nasirzadehdizaji ${ }^{3}$ \\ ${ }^{1}$ Dept. of Geomatic Engineering, Bulent Ecevit University, Zonguldak, Turkey- sabdikan@ beun.edu.tr \\ ${ }^{2}$ Dept. of Geomatic Engineering, Cukurova University, Ceyhan, Adana, Turkey-aliihsan_sekertekin@ @otmail.com \\ ${ }^{3}$ Dept. of Geomatic Engineering, Yildiz Technical University, Istanbul, Turkey- (mustuner, fbalik)@yildiz.edu.tr, \\ nasirzadeh.rouhollah@gmail.com
}

Commission III, WG III/2

KEY WORDS: Sentinel-1, backscatter, SAR, maize, crop growth monitoring, land use

\begin{abstract}
:
Temporal monitoring of crop types is essential for the sustainable management of agricultural activities on both national and global levels. As a practical and efficient tool, remote sensing is widely used in such applications. In this study, Sentinel-1 Synthetic Aperture Radar (SAR) imagery was utilized to investigate the performance of the sensor backscatter image on crop monitoring. Multi-temporal C-band VV and VH polarized SAR images were acquired simultaneously by in-situ measurements which was conducted at Konya basin, central Anatolia Turkey. During the measurements, plant height of maize plant was collected and relationship between backscatter values and plant height was analysed. The maize growth development was described under Biologische Bundesanstalt, bundessortenamt und CHemische industrie (BBCH). Under BBCH stages, the test site was classified as leaf development, stem elongation, heading and flowering in general. The correlation coefficient values indicated high correlation for both polarimetry during the early stages of the plant, while late stages indicated lower values in both polarimetry. As a last step, multi-temporal coverage of crop fields was analysed to map seasonal land use. To this aim, object based image classification was applied following image segmentation. About $80 \%$ accuracies of land use maps were created in this experiment. As preliminary results, it is concluded that Sentinel-1 data provides beneficial information about plant growth. Dual-polarized Sentinel-1 data has high potential for multi-temporal analyses for agriculture monitoring and reliable mapping.
\end{abstract}

\section{INTRODUCTION}

Accurate extraction of the agricultural crop pattern and its spatio-temporal monitoring have substantial importance for long term agricultural management. It also has a vital socioeconomic impact for food resources and sustainability of agricultural activities. Moreover, changes in climate and population effects demand on food. Alexandratos and Bruinsma (2012) stressed that the world crop production will be $60 \%$ higher in 2050 than that of 2006. It is needed to maintain sufficient production of crops and it is crucial to forecast crop production for decision makers where food security is vulnerable (FAO 2017).

New space-borne remote sensing missions provide opportunity to monitor agricultural applications and produce up-to-date information in space and time domain. Optical remote sensing is one of the most common used data source for obtaining crop variables such as yield estimation (Alganci et al., 2014), biomass estimation (L'opez-Serrano et al., 2016), biophysical variables (Frampton et al., 2013) and crop type mapping (Ustuner et al., 2016) due to sensitivity of crop leaves to visible and infrared bands.

Contrary to optical sensors, Synthetic Aperture Radar (SAR) sensors are capable to acquire images under all weather conditions which makes it suitable for long term and multi seasonal monitoring (Liao et al., 2018). Current SAR systems have become increasingly a beneficial source to help agriculture monitoring (Soria-Ruiz et al., 2009, Canisius et al., 2017).

Previous studies performed the supervised pixel based classification on Sentinel-1 data for land cover mapping and yielded accuracy higher than $90 \%$ by utilizing backscatter values of single dual polarimetric data (Abdikan et al. 2016). McNairn et al. (2014) investigated corn and soybeans using TerraSAR-X and Radarsat-2 for their growing season monitoring. The study concluded that both sensors are capable of high accurate map production $(>90 \%)$ at the end of the early season using pixel based decision tree classification. Sonobe et al (2014) compared random forest and classification and regression tree (CART) methods using multi-temporal TerraSAR-X dual polarimetric data. Even the classification results of random forest are higher than CART, maize indicated lower accuracies than other five crop types. Jiao et al. (2014) applied object oriented classification for the multi-temporal crop monitoring using polarimetric Radarsat-2 images. Although overall accuracies are higher than $80 \%$, polarimetric decomposition achieved higher accuracies comparing to linear polarizations. However, comparing individual crop class accuracies oat and wheat obtained lower accuracies. Relation between corn height and multi temporal Radarsat-2 images was conducted by (Liao et al., 2018). They showed that early growing season has strong correlation with HV band of data.

\footnotetext{
* Corresponding author
} 
In this study, potential of dual polarized Sentinel-1 backscatter data for maize growth monitoring is investigated. Discriminate crops and produce reliable and accurate crop map for cultivated areas using multi-temporal analysis is conducted. We analysed multi-temporal C-band VV and VH polarized Sentinel-1 SAR data to investigate the backscatter behaviour of maize crop in the sense of crop pattern mapping in central Turkey. Finally, object based image analysis is applied to achieve multi-temporal crop mapping

\section{MATERIALS AND METHODOLOGY}

\subsection{Study Area: Konya}

The test area is located at Konya basin, central Anatolia Turkey, which is approximately $40 \mathrm{~km}^{2}$. It has an arid to semi-arid climate and due to the dense agricultural activities, the water consumption of irrigation has increased. The study area is shown in Figure 1.
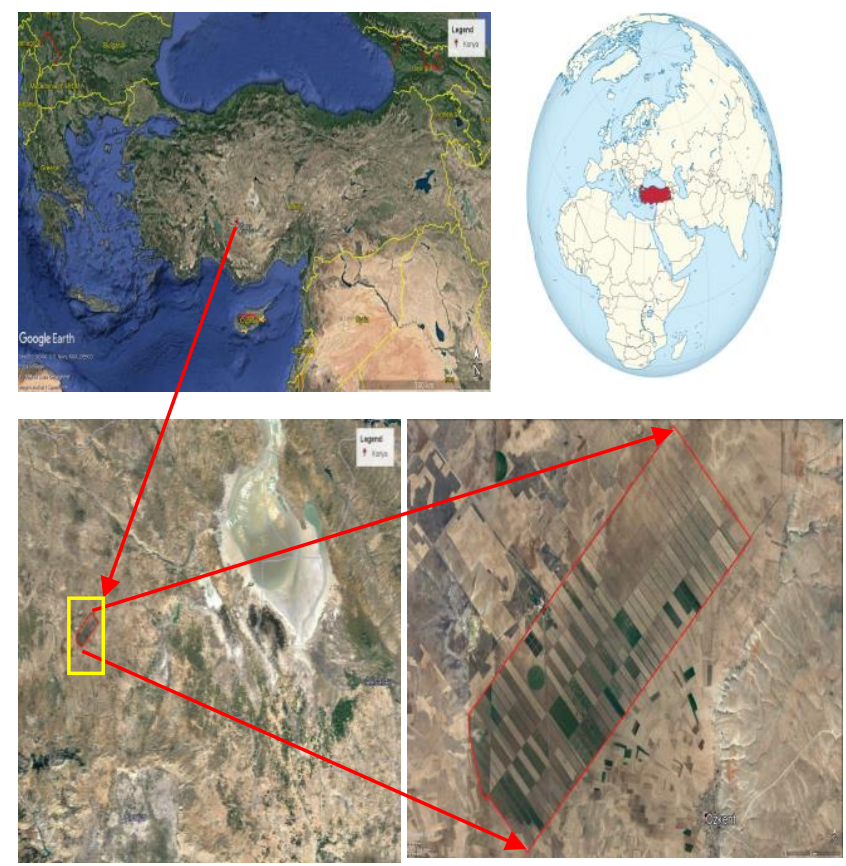

Figure 1. Study area

\subsection{Sentinel-1}

Sentinel-1 images were acquired in descending orbit direction, Interferometric Wide swath (IW) mode Level-1 Single Look Complex product which contains phase and amplitude information (Table 1). In the pre-processed images, only amplitude information was used. Pre-processing steps follow as radiometric calibration, thermal noise removal, TOPSAR deburst and merge, multi-look, topographic correction using SRTM 1Sec HGT data and co-registration were performed with open source tools of Sentinel Application Platform (SNAP) software (SNAP, 2017). Multi-look of four at the range and one at azimuth was applied and the spatial resolution is determined as 15 meters. As a last step of the pre-processing chain, pixel digital numbers were converted to sigma nought in decibel
(dB). A false colour RGB composite of multi-temporal image is shown in Figure 2.

\begin{tabular}{|l|l|l|}
\hline Characteristics of Sensor & No & \multicolumn{1}{|c|}{ Date } \\
\hline Satellite: Sentinel-1 & 1 & 13 June 2016 \\
\hline Wavelength: C-band & 2 & 02 July 2016 \\
\hline Imaging mode: IW-SLC & 3 & 31 July 2016 \\
\hline Orbit: Descending & 4 & 24 August 2016 \\
\hline Resolution: 2.33m (Rg.) x & & \\
13.93m (Az.) & & \\
\hline Polarization: VH and VV & & \\
\hline
\end{tabular}

Table 1. Specifications of Sentinel-1

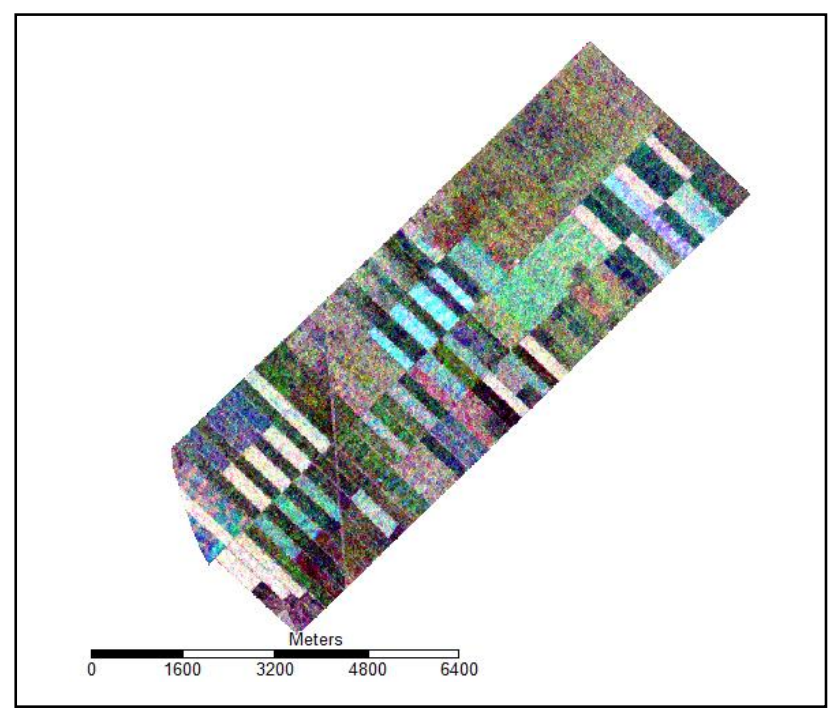

Figure 2. RGB composite of Sentinel-1 (R: 20160613, G: 20160702, B: 20160731)

\subsection{In-situ Measurements}

For this study, a field work was conducted in the spring-summer season of 2016 and maize fields were under investigation. During the field work, geometric properties of plants (i.e plant height and cover) were measured and recorded simultaneously with the SAR data acquisition period. For the sensitivity analysis of SAR backscatter to crops a time series of four remotely sensed Sentinel-1 SAR data were acquired as 13 June, 02 July, 31 July and 24 August in 2016. During the first acquisition, seven fields and in other three acquisitions twenty maize fields were visited to collect in situ measurements.

The maize growth development period generally consists of two stages as vegetative and reproductive stages. In this development period, plant indicates a variety of phenological stages which has been described under Biologische Bundesanstalt, bundessortenamt und $\mathrm{CHemische}$ industrie (BBCH) (Meier 2001). Plant height is one of the measurements which represents its growth rate. The test site covers maize, potato, summer wheat, sunflower, and alfalfa crops for the vegetation season of 2016 summer season. The largest field is 4 $\mathrm{km}^{2}$ and the smallest one has approximately 3,33 ha. size.

The in-situ measurements exhibited that maize has four stages during the field works and SAR data acquisitions. These BBCH stages are classified as leaf development, stem elongation, heading and flowering in general. From each field, five plant 
measurement were collected randomly and their mean value is calculated to represent the plant height of each field.

\begin{tabular}{|l|l|l|}
\hline Field works & $\begin{array}{l}\text { Crop growth stages } \\
\text { (BBCH) }\end{array}$ & $\begin{array}{c}\text { Image acquisition } \\
\text { dates }\end{array}$ \\
\hline 12 June 2016 & leaf development & 13 June 2016 \\
01-02 July 2016 & stem elongation & 02 July 2016 \\
31 July 2016 & heading & 31 July 2016 \\
24-25August 2016 & flowering & 24 August 2016 \\
\hline
\end{tabular}

Table 2. In situ measurements of test site

\subsection{Land Use Mapping}

Object based image classification was conducted to map the multi temporal coverages of the seasonal crops. Before image classification of the multi-temporal Sentinel-1 SAR data, enhanced Lee filter was applied to reduce the speckle effects. In situ vegetative measurements and as well as in situ photographs which were taken during the visiting of crop fields were used for the validation of land use maps.

Before the classification step, a stacked image of $\mathrm{VV}, \mathrm{VH}$ and ratio $(\mathrm{VH} / \mathrm{VV})$ was generated for each image. For the crop mapping, seeded region growing algorithm was used for the image segmentation and minimum distance classification method are applied to discriminate the selected classes to provide reliable crop map (Conrad et al., 2015). Land use maps consist of five seasonal crops as potato, maize, wheat, alfalfa and sunflower. Quality of the maps are evaluated with overall accuracy and kappa statistics which are calculated from confusion matrix.

\section{RESULTS AND DISCUSSIONS}

\subsection{Backscatter analysis}

Mean backscatter coefficient values for each field were determined and the correlation between the in situ measurements was evaluated. In all visited fields, the backscatter values showed similar trends in four periods. To reduce the effects of mixture of the classes, the polygons were set at appropriate distance from the edges of the field borders and homogeneous pixels were selected for the evaluation. While the values of pixels change between $-8 \mathrm{~dB}$ and $-14 \mathrm{~dB}$ in $\mathrm{VV}$ polarized images, the values of them varies between $-11 \mathrm{~dB}$ and $-22 \mathrm{~dB}$ in $\mathrm{VH}$ polarized images.

In Figure 3 and 4 , mean backscattering coefficient values $\left(\sigma_{\mathrm{VH}}\right.$, $\sigma \mathrm{vv})$ of each field were determined and the correlation between the in situ measurements was presented. As it is evident from the graphs, SAR backscattering coefficient is more sensitive to plant height at the beginning stage of crop growth compared to the later stage. It is most probably because of that at early growth stage of maize, $\sigma \mathrm{vH}$ and $\sigma \mathrm{vV}$ represent volumetric scattering better than later stages. As the maize becomes taller and densely covers the area, the SAR penetration is limited and the backscattering coefficient is reduced due to the attenuation effect.

Considering the correlation between the maize height and SAR backscattering coefficient, it was observed that the maize height was highly correlated with $\sigma \mathrm{vH}$ and $\sigma \mathrm{vv}$ when the height was less than $150 \mathrm{~cm}$.

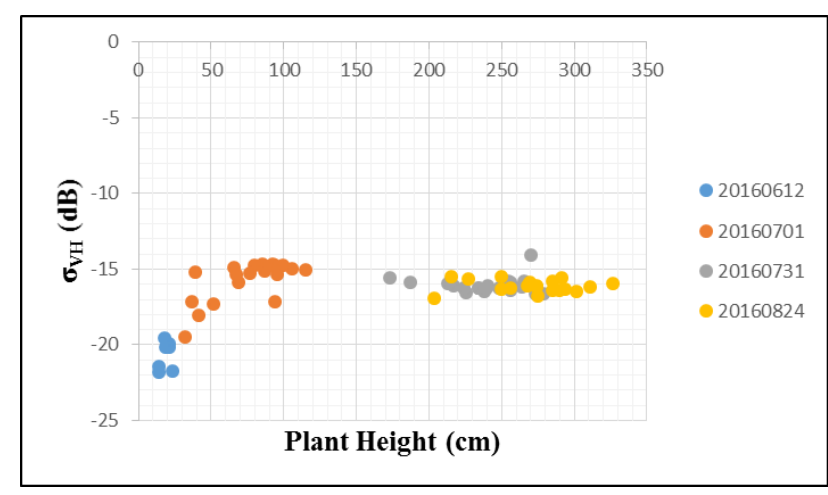

Figure 3. Correlation between $\sigma \mathrm{vH}$ and Plant Height.

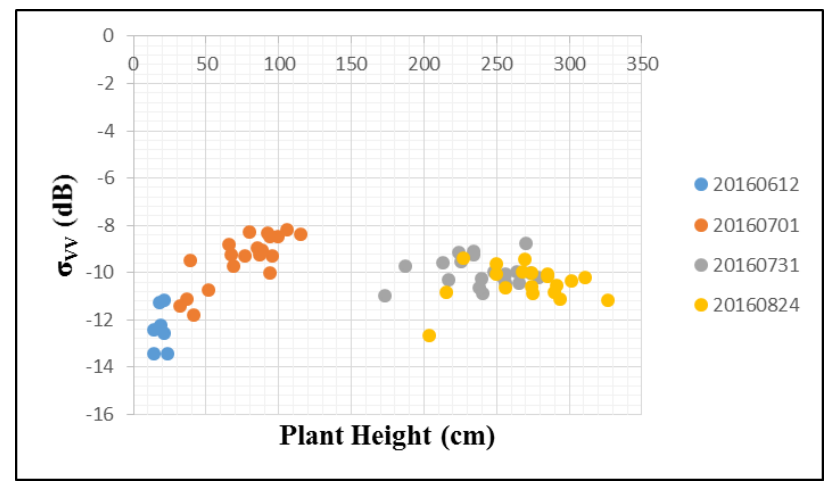

Figure 4. Correlation between $\sigma \mathrm{vv}$ and Plant Height.

As the maize height became taller than $150 \mathrm{~cm}$, the sensitivity of backscattering coefficient to the maize height decreased. It was observed that correlation coefficients between the maize height and SAR backscattering coefficient $(\sigma \mathrm{vH}, \sigma \mathrm{vv})$ were significantly correlated as 0.76 and 0.80 , respectively at the early stage (Table 3). Similarly, Liao et al (2018) concluded that Radarsat-2 polarimetric data gave higher relationship with crop height at the early stage of maize growing and lower relationship at the later stage.

\begin{tabular}{|c|c|c|}
\hline \multirow{2}{*}{$\begin{array}{c}\text { SAR Backscatter } \\
(\mathbf{d B})\end{array}$} & \multicolumn{2}{|c|}{ Maize Height $\mathbf{( H )}$} \\
\cline { 2 - 3 } & $\mathbf{H}<\mathbf{1 5 0} \mathbf{~ c m}$ & $\mathbf{H}>\mathbf{1 5 0} \mathbf{~ c m}$ \\
\hline $\mathrm{VV}$ & 0.80 & 0.02 \\
\hline $\mathrm{VH}$ & 0.76 & 0.18 \\
\hline
\end{tabular}

Table 3. Coefficient of determination (R2) between in-situ measured corn height and Sentinel-1 backscattering coefficient.

\subsection{Accuracy assessment of land use}

Land use maps were produced after object-based image classification and for each acquisition, overall accuracies were calculated. Additionally produce and user accuracies for each class are extracted from confusion matrix.

The results showed that all maps reached high overall accuracies of more than $80 \%$ (Table 4). Among them third stage of the growing indicated the highest accuracy with $96 \%$. Considering maize crop most accurate map with $98 \%$ and kappa with 0.95 was produced at third stage of the growing on $31 \mathrm{Jul}$. 2016. The land use maps are shown in Figure 5. 


\begin{tabular}{|l|l|l|l|l|}
\hline & \multicolumn{2}{|l|}{ 13 Jun 2016 } & \multicolumn{2}{l|}{ 02 Jul 2016 } \\
\hline & Prod. Ac. & User Ac. & Prod. Ac. & User Ac. \\
\hline Potato & 0,99 & 0,99 & 1,00 & 0,75 \\
\hline Maize & 0,94 & 0,71 & 0,72 & 0,99 \\
\hline Alfalfa & 0,99 & 0,99 & 0,91 & 0,98 \\
\hline Wheat & 0,99 & 0,96 & 0,97 & 0,77 \\
\hline Sunflower & 0,78 & 0,95 & 0,84 & 0,99 \\
\hline Overall & 0,95 & 0,88 & \\
Kappa & 0,94 & 0,85 & \multicolumn{3}{|l}{} \\
\hline
\end{tabular}

\begin{tabular}{|l|l|l|l|l|}
\hline & \multicolumn{3}{|l|}{ 31 Jul 2016 } & \multicolumn{2}{l|}{ 24 Aug 2016 } \\
\hline & Prod. Ac. & User Ac. & Prod. Ac. & User Ac. \\
\hline Potato & 0,97 & 0,97 & 0,68 & 0,78 \\
\hline Maize & 0,98 & 0,87 & 0,85 & 0,69 \\
\hline Alfalfa & 1,00 & 1,00 & 1,00 & 0,99 \\
\hline Wheat & 0,79 & 0,96 & 0,71 & 0,69 \\
\hline Sunflower & 0,95 & 1,00 & 0,88 & 0,96 \\
\hline Overall & 0,96 & 0,84 & \\
Kappa & 0,95 & 0,80 & \\
\hline
\end{tabular}

Table 4. Accuracy assessment of land use maps.
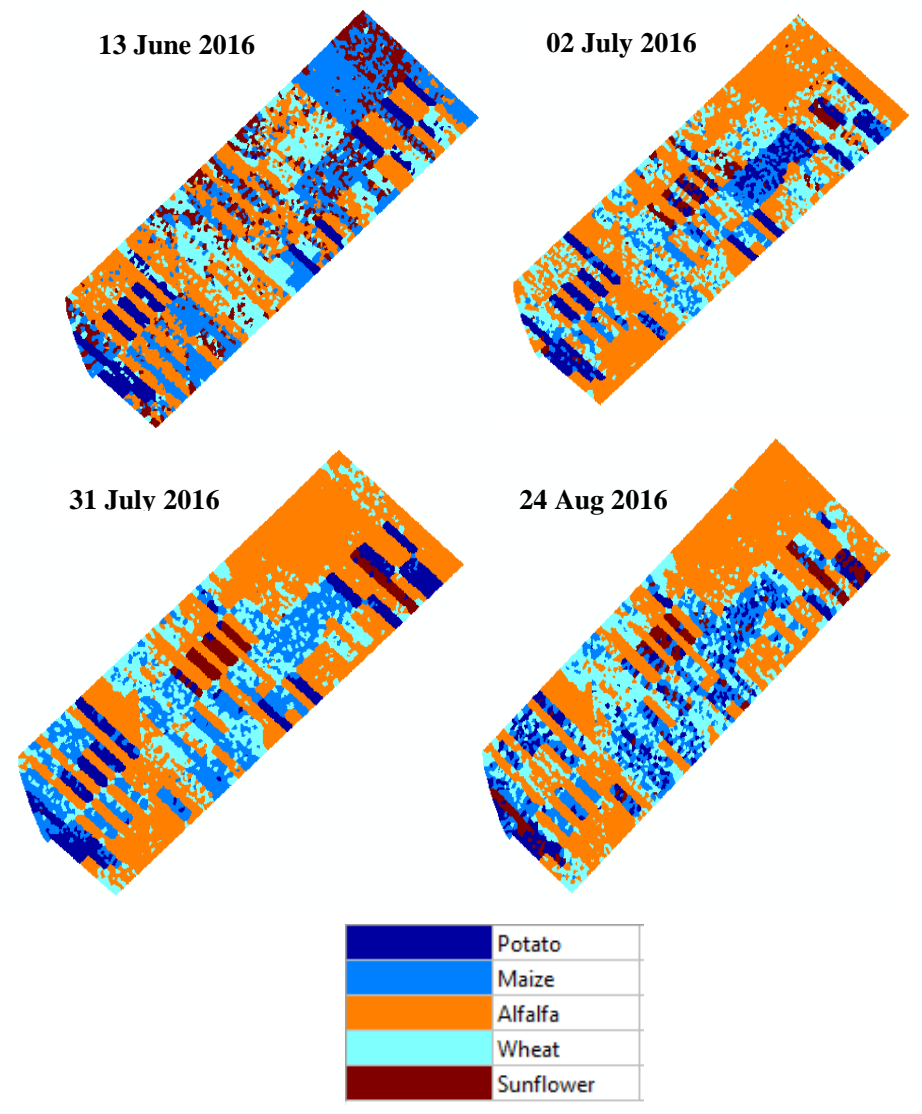

Sentinel-1 allowed us to discriminate the crops and yields about $80 \%$ accuracies of land use maps in our experiment. Our results encourage that the multi-temporal use of dual polarized C-band Sentinel-1 SAR data for the development of agriculture monitoring system which may play a significant role for the accurate crop assessment.

For further investigation of the relationship between backscatter values of multi-temporal Sentinel-1 data and crop height, polarimetric and spatial features will be incorporated to improve the results. Furthermore, the relationship between crop height and other crop types will be evaluated as a follow-up study.

\section{REFERENCES}

Abdikan, S., Sanli, F. B., Ustuner, M., and Calò, F., 2016. Land Cover Mapping Using Sentinel-1 SAR Data, Int. Arch. Photogramm. Remote Sens. Spatial Inf. Sci., XLI-B7, 757-761, https://doi.org/10.5194/isprs-archives-XLI-B7-757-2016, 2016.

Alganci U., Ozdogan M., Sertel E., Ormeci E., 2014. Estimating maize and cotton yield in southeastern Turkey with integrated use of satellite images, meteorological data and digital photographs. Field Crops Research, 157(15), pp. 8-19.

Alexandratos, N. and Bruinsma, J. 2012. World agriculture towards 2030/2050: the 2012 revision. ESA Working paper No. 12-03. Rome, FAO.

Canisus F., Shang J., Liu J., Huang X., Jiao X., Geng X., Kovacs J.M., Walters D., 2017. Tracking crop phenological development using multi-temporal polarimetric Radarsat-2 data, Remote Sensing of Environment, https://doi.org/10.1016/j.rse.2017.07.031.

Conrad O., Bechtel B., Bock M., Dietrich H., Fischer E., Gerlitz L., Wehberg J., Wichmann V., and Böhner J., 2015. System for Automated Geoscientific Analyses (SAGA) v. 2.1.4. Geosci. Model Dev., 8, pp. 1991-2007.

FAO 2017. Review of the available remote sensing tools, products, methodologies and data to improve crop production forecasts. ISBN 978-92-5-109840-0 Rome.

Frampton W.J., Dash J., Watmough G., Milton E.J., 2013. Evaluating the capabilities of Sentinel-2 for quantitative estimation of biophysical variables in vegetation. ISPRS Journal of Photogrammetry and Remote Sensing 82, pp. 83-92.

Jiao X., Kovacs J. M., Shang J., McNairn H., Walters D., Ma B., Geng X., 2014. Object-oriented crop mapping and monitoring using multi-temporal polarimetric RADARSAT-2 data. ISPRS Journal of Photogrammetry and Remote Sensing 96, pp.38-46.

Figure 5. Multi-temporal land use maps

\section{CONCLUSIONS AND FUTURE PERSPECTIVES}

In this study, sensitivity of Sentinel-1 SAR image to crop height was evaluated. The relationship between maize plant height and $\sigma_{\mathrm{VH}}$ and $\sigma_{\mathrm{VV}}$ was investigated. It was demonstrated that early stages of plant growth have higher correlation and opposite to this, later stages showed lower correlation. Additionally,

Liao C., Wang J., Shang J., Huang X., Liu J. and Huffman T., 2018. Sensitivity study of Radarsat-2 polarimetric SAR to crop height and fractional vegetation cover of corn and wheat, International Journal of Remote Sensing, 39, 5, pp. 1475-1490.

López-Serrano P. M., López-Sánchez C. A., Álvarez-González J. G. and García-Gutiérrez J., 2016. A Comparison of Machine Learning Techniques Applied to Landsat-5 TM Spectral Data for Biomass Estimation, Canadian Journal of Remote Sensing, 42:6, 690-705 
McNairn H., Kross, A., Lapen, D., Caves, E., Shang, J., 2014.

Early season monitoring of corn and soybeans with

TerraSAR-X and RADARSAT-2. International Journal of Applied Earth Observation and Geoinformation, 28, pp. 252-259.

Meier 2001. Growth stages of mono- and dicotyledonous plants. In: Meier, U. (Ed.), BBCH Monograph, (158 pp).

SNAP Development Team, 2017. Sentinel Application Platform Software, http://step.esa.int/main/toolboxes/snap/ (20 October 2017)

Sonobe R., Tani H., Wang X., Kobayashi N., Shimamura H., 2014. Random forest classification of crop type using multitemporal TerraSAR-X dual-polarimetric data. Remote Sensing Letters, 5(2), pp. 157-164.

Soria-Ruiz J., Fernandez-Ordonez Y., McNairn H., 2009. Corn Monitoring and Crop Yield Using Optical and Microwave

Remote Sensing, Geoscience and Remote Sensing, InTech, pp. 407-419

Ustuner M., Esetlili MT, Sanli FB, Abdikan S, Kurucu Y, 2016. Comparison of crop classification methods for the sustanaible agriculture management. J. Environ. Prot. Ecol, 1(1), pp. 648655 . 